\title{
Psychological adjustment to acquired facial disfigurement: Personality characteristics, self-concept and satisfaction with social support - a longitudinal study
}

\author{
Ajuste psicológico ao desfiguramento facial adquirido: Características \\ de personalidade, autoconceito e satisfação com o suporte social - \\ estudo longitudinal
}

J. Mendes, R. Rego, T. Moss, D. Alcaidinho

ORIGINAL TITLE | ARTIGO ORIGINAL

\begin{abstract}
We intend to contribute towards a better understanding of the variables that affect the Schematic Investment and Self-consciousness of the appearance of those who suffer from acquired facial disfigurement. The sample consisted of 67 individuals who have been submitted to plastic and reconstructive surgery and completed a questionnaire evaluating the influence of personality traits, optimism, self-concept, emotions and perception of satisfaction with social support, and with the perception of appearance during their admittance to the hospital, and 12 months after the surgery. There were meaningful statistical differences in both evaluation moments for the variables Neuroticism, Extraversion, Openness, Agreeableness, Conscientiousness, Optimism, Positive and Negative Affect, Self-Concept, and Social Support Satisfaction. In both evaluations, Self-conscientiousness of Appearance reveals a positive relationship with Neuroticism and negative relation with Self-concept. Results show that Schematic Investment and Self-conscientiousness of appearance vary in time and that there are variants that influence the psychological adjustment to acquired facial disfigurement.

Keywords: personality, self-concept, social support, schematic investment of appearance, selfconsciousness of appearance, acquired facial disfigurement
\end{abstract}

\section{RESUMO}

Propõe-se com este estudo, contribuir para uma melhor compreensão das variáveis que afetam o investimento esquemático e autoconsciência da aparência em indivíduos com desfiguramento facial adquirido. A amostra constitui-se por 67 indivíduos submetidos a cirurgia plástica e reconstrutiva, tendo respondido a um conjunto de questionários que avaliam a influência dos traços de personalidade, otimismo, autoconceito, emoções, perceção da satisfação com o suporte social e preocupações com aparência, durante o internamento e 12 meses após a intervenção cirúrgica. Em ambos os momentos de avaliação, houve evidências estatísticas para as variáveis Neuroticismo, Extroversão, Abertura à Experiência, Amabilidade, Conscienciosidade, Otimismo, Afeto Positivo e Negativo. Nas duas avaliações, a Autoconsciencia da Aparência revela uma relação positiva com a dimensão Neuroticismo e uma relação negativa com o Autoconceito. Os resultados revelam que o Investimento Esquemático e a Autoconsciência da Aparência variam no tempo, não existindo variantes que influciem o ajustamento psicológico ao desfiguramento facial aquirido.

Palavras-chave: personalidade, autoconceito, suporte social, investimento esquemático da aparência, autoconsciência da aparência, desfiguramento facial aquirido

Submitted: 12.18.2018 | Accepted: 06.18.2019

José Mendes, INTELECTO - Psychology \& Research, Ponta Delgada, Açores e Inst. Psic. Cog.., Des. Humano e Social, Univ Coimbra, Portugal. Rui Rego, Research Center for Spatial and Organizational Dynamics, Faro, Portugal. Tim Moss, Univ. of the West of England, UK. Durval Alcaidinho, INTELECTO - Psychology \& Research, e Hospital Divino Espírito Santo, Ponta delgada, Açores, Portugal.

Endereço para correspondência: José Mendes. Rua do Monte, 52B, L, R/C Esq..- Nascente, 9500-451, Ponta Delgada. Portugal e-mail: josemendes@intelecto.pt 
As body image is influenced by a complex interaction of variables (Cash, 2004), it is described as a central characteristic of self-concept for some individuals, making them more sensitive to the internalization of information regarding weight, shape and the size of the body The face is considered to be the part of the body that reflects emotions, beauty, and attraction, thus distinguishing one individual from another, and it is difficult to ignore the importance of the face in interaction and social judgment, especially during an initial phase (Callahan, 2005; Elks, 1990; Rumsey \& Harcourt, 2012). Based on this idea it seems clear that facial disfigurement has an impact on the self-concept, which, which in turn is moderated by the perceived reactions of others regarding their appearance and attractiveness (Maddern, Cadogan, \& Emerson, 2006).

According to Maddern, et al. (2006), self-concept may be related to social challenges felt by individuals who suffer from a facial disfigurement and that are moderated by the perceived reactions of others regarding their appearance and attractiveness.

Facial disfigurement has a deep impact on the daily life of an individual because it influences communication with the outside world, which is vital to health, wellness, and survival (Soni et al., 2010), and consequently in the person's personality (Bhattacharya, 2012). The same authors refer that those who suffer from facial disfigurement could be confronted with many problematic situations, forcing them to take a critical stand and to choose options that are somewhat conscientious or supported, influencing the course of their lives and their wellness. There is a general simple and common idea of what a "normal" face looks like (Partridge, 2003), however, small concerns with appearance due to (scars, disfigurement, obesity, and others) may generate severe suffering among some people, thus given way to possible dysfunctional behaviors (Carr, Harris, \& James, 2000; Costa, Nogueira, Souza-Lima,
Mendonça, \& Leles, 2014).

Facial disfigurement has a deep impact on the daily life of an individual because it influences communication with the outside world, which is vital to health, wellness, and survival (Soni et al., 2010). The same authors refer that those who suffer from facial disfigurement could be confronted with many problematic situations, forcing leading them to take a critical stand and to choose options that are somewhat conscientious or supported, influencing the course of their lives and their wellness. The face is strongly associated with an individual's personality and when there is an alteration there could be strong feelings of depersonalization (Brill, Clarke, Veale, \& Butler, 2006).

The multidimensional concept of disfigurement (Clarke, Thompson, Jenkinson, Rumsey, \& Newell, 2014; Lansdown, 1997), reinforces the need for a deeper study as deficiencies in interpersonal functioning and the difficulties in detecting emotions may contribute towards the lack of the affectionate support that is linked to intimate relations and influence some social situations (Csukly et al., 2011).

After a facial surgical intervention, the individual might lose functions such as speech, communication, or the ability to smell and taste, or even the appearance of a "normal" face. These changes could be acute threats to self-image and self-confidence, which can cause high levels of depression and the possibility of suicidal thoughts (Kugaya, Akechi, Okamura, Mikami, \& Uchitomi, 1999). As the adjustment could be influenced by different factors, Partridge (2003) mentions that there are no ideal answers for the adjustment to facial disfigurements, therefore more studies are required in order to enlighten this matter. The same author mentions the need for a mutually reinforced intervention on facial reconstruction and psycho-social rehabilitation. Most individuals with facial disfigurement are defined by a negative self-perception and an added difficulty to 
interact socially (Rumsey \& Harcourt, 2004). In these cases, social isolation could also increment some psychological disorders (Tagkalakis $\&$ Demiri, 2009).

Ribeiro (2011), describes social support as a resource that is available to individuals and social circles, allowing them to believe that they are loved, appreciated and worthy, and part of a communication network of common obligations. Nonetheless, the ability of an individual to deal with alterations on their face is described by the social meaning of disfigurement, life story, family support and stage of development (Bradbury, 2012), thus the need to change negative aspects of social behaviour in the presence of an individual suffering from facial disfigurement (Bessell, Clarke, Harcourt, Moss, \& Rumsey, 2010).

Identity may be important not only in terms of facial recognition but also in terms of attraction and sexual identity (Gwanmesia, Clarke, \& Butler, 2011), given the fact that self-evaluation of appearance is part of the measure that individuals consider their appearance fits into their identity, allowing them to assess their personal worth (Nazaré, Moreira, \& Canavarro, 2010). Swami et al. (2013) defended that a negative body image may be associated with individuals who experience more negative emotional states.

The evaluation of general aspects and the concern over the appearance of the presentation of any external image of an individual remains relatively unexploited (Rosser, et al., 2010). We know that the interaction between an individual and social factors influence the degree of acceptance of the acquired disfigurement (Rumsey \& Harcourt, 2004). The research regarding this problem sporadically appears in the literature. Thus the need for research that aims to deepen our understanding of the relationship between facial disfigurement and personality.

The face is strongly associated with an individual's personality and when there is an alteration there could be strong feelings of depersonalization (Brill, et al., 2006). The physical appearance of people can have a profound impact on their social interactions and the accumulation of these experiences is reflected in the way people choose to introduce themselves to others (their personality) (Hagedoom \& Molleman, 2006). All in one way or another tend to make the first judgments about others based on the faces and based on this observation the first impressions on them are formed. Individuals with facial disfigurement acquired in addition to self-observing also deal daily with the first reactions they encounter when meeting others. People with facial disfigurement are discriminated against throughout life. Jamrozik, Oraa-Ali, Sarver, and Chatterjee (2019) conducted a study that clearly showed how the reaction to facial disfigurement rests on stereotypes such as "disfigured is bad." In their research, they noted how people made judgments to disfigured individuals before and after receiving corrective treatment to disfigure. Exposed to photographs, respondents reported lower emotional valence (ie, more negative emotion), greater arousal and less dominance when viewing the subjects in the pre-treatment phase (vs. post-treatment). Pretreatment individuals were seen more negatively in terms of personality (e.i. emotional stability, awareness), internal attributes (e.i. happiness, intelligence) and social attributes (e.i. reliability, popularity). In addition, the perception of people with pre-treatment disfigurement differed from those who had a facial correction. In the pre-treatment phase, they were considered less sociable and happy, less dominant, emotionally unstable, and tended to be viewed more as objects of curiosity than others. According to Jamrozik, et al. (2019), these results suggest that the negative stereotype of people with a facial disfigurement can lead to discrimination in multiple socio-cultural contexts that lead to loss of quality of life. Losee, Fletcher, and Gorantlia (2012) and Wang et al. (2018) sate that facial deformity can cause significant 
functional and psychological injury and consequently preclude the individual from meaningful interactions.

Given the intrinsic complexity of the psychological adjustment to acquired facial disfigurement, a longitudinal study was conducted in individuals, who after plastic/reconstructive surgery, suffer from acquired facial disfigurement and how some personality characteristics (Neuroticism, Extraversion, Openness, Agreeableness, Conscientiousness, Optimism, Positive and Negative Affect, Self-Concept and Social Support Satisfaction) relate to this problematic.

\section{METHODS}

67 individuals participated in this study, who after facial surgery, participated on two (12-month interval) evaluation instances. Their average age is 42.4 years $(S D=18.83)$. After surgery, $100 \%$ of the participants had a scar on their face. Table 1 present the characterization of participants.

Table 1

Characterization of the participants $(N=67)$

\begin{tabular}{|c|c|c|c|}
\hline Gender & \multicolumn{3}{|c|}{ Cause of the Disfigurement } \\
\hline Male & 64.2 & Disease & 56.7 \\
\hline Female & 35.8 & Trauma & 43.3 \\
\hline Marital status & \multicolumn{3}{|c|}{ Origin of the Disfigurement } \\
\hline Single & 40.3 & Accident & 11.9 \\
\hline Married & 47.8 & Assault & 17.9 \\
\hline Divorced & 1.5 & Cancer & $\simeq 55.2$ \\
\hline Common law & 10.4 & Burns & 14.9 \\
\hline Area of residence & \multicolumn{3}{|c|}{ Concerns with Appearance } \\
\hline Great Urban Area & 50.7 & A little & 26.9 \\
\hline Small Urban Area & 35.8 & Indifferent & 16.4 \\
\hline Great Rural Area & 6.0 & A lot & 44.8 \\
\hline Small Rural Area & 7.5 & Too much & 11.9 \\
\hline
\end{tabular}

\section{Instruments}

DAS24 [Derriford Appearance Scale- Revised] (Moss, Carr, \& Harris, 1996) had the subjacent construct to measure the self-consciousness of appearance, in 24 items, answered on a Likert type scale, with 6 additional questions. The 24 items had the objective of evaluating the manner in which they feel and behave regarding the characteristics that are bothering them, having been quoted via the following options to answer: " $0=N / A$ (not applicable), $1=$ Never/Almost never, $2=$ Sometimes, $3=$ Frequently and $4=$ Almost always" for items $3,5,7,9,12,13,15,18,19$, 21, 24 and " $1=$ Nothing, 2=Lightly, 3=Moderately and $4=$ Extremely" for the rest of the items.
The psychometric study of the Portuguese version (Moreira \& Canavarro, 2007) reveals a good index of internal consistency $(\alpha=.91)$; $(\mathrm{KMO}=.93)$, Bartlett's spherical test $\left(\mathrm{X} 2_{(276)}=\right.$ 4474.812; $p=.001)$.

ASI-R [The Appearance Schemas Inventory Revised] - (Cash, Melnyk, \& Hrabosky, 2004; Nazaré et al., 2010), which is made up by two factors (Salience self-evaluation and Motivational self-evaluation), evaluates the Schematic Investment on appearance (Cash et al., 2004). The 20 items, in a five-point Likert type scale, vary between 1 (I strongly disagree) and 5 (I strongly agree), evaluating the efforts made by an individual in keeping or increasing their 
physical attractiveness and to manage their appearance. The higher this result is, the higher are the levels of the Schematic Investment relating to appearance. The Portuguese version of this instrument (Nazaré et al., 2010) reveals psychometric characteristics that are similar to the original version $(\alpha=.89)$.

ICAC [Inventário Clínico de Auto-Conceito] (Vaz Serra, 1986), evaluates emotional and social aspects of the self-concept via a one-dimensional scale, in a total of 20 items similar to the Likert type, "1- I do not agree, 2- I agree on a bit, 3- I moderately agree, 4- I agree on a lot, and 5-I fully agree”, revealing internal consistency $(\alpha=.84)$. Higher values correspond to a better self-concept.

PANAS [Positive and Negative Affect Schedule] - (Galinha \& Pais-Ribeiro, 2005) evaluates specific emotional states, made up of 20 emotions organized on two subscales: positive affect $(\alpha=.86)$ and negative affect $(\alpha=.89)$ with a correlation between the sub-scales close to zero $(r=-.10)$. The replies vary between the following "1- none or very slightly, 2- a little, 3-moderately, 4- a lot, and 5-extremely".

NEO-FFI [NEO- Five-Factor Inventory] (Magalhães et al., 2014) involves a dimensional representation of interpersonal differences at the personality level, and through this model it is possible to agglomerate behaviour, the emotional and cognitive tendencies of people in five large categories: Neuroticism ( $\alpha=.81)$, Extraversion $(\alpha=.75)$, Openness $(\alpha=.71)$, Agreeableness $(\alpha=.72)$, Conscientiousness $(\alpha=.81)$, made up of 60 items, which in the original allows for a reliable version of the model of the five factors. The items are answered on a 5 point Likert type scale, from 1 (I strongly disagree) to 5 (I strongly agree).

LOT-R [Life Orientation Test - Revised] (Laranjeira, 2008) evaluates optimism versus pessimism through 10 items, on a scale similar to Likert with answers varying between " $1-I$ largely disagree, 2- I disagree, 3- neutral, 4- I agree and 5-I strongly agree", inverting items 3, 7 and 9. Six items indicate optimism and the rest are considered to be distracting items, revealing a Cronbach alpha coefficient equal to .71.

ESSS [Social Support Satisfaction Scale] (Pais-Ribeiro, 1999) evaluates the perception of satisfaction with the existing social support. The scale is made up of 15 sentences together with affirmations, on a 5 point Likert type scale ranging from "5-totally agree", 4- I agree with the most part", "3-I do not agree and I do not disagree", "2-I disagree with most part" and "1I totally disagree", presenting an internal consistency of the total of the scale $\alpha=.85$.

\section{Procedures}

Patients were approached, in a Hospital admittance unit for reconstructive plastic surgery, and who due to disease or trauma had been subjected to facial surgery. After explaining the objectives and the instances of evaluation (first evaluation during the admittance post-surgical and the second evaluation 12 months after the surgery) of this study, the informed consent was read and signed by both parties (participants and researcher). The participants were informed that they may give up participating in the study at any point in time. 92 individuals participated in the first evaluation, 13 were excluded because they hadn't fully answered the questionnaires, and 12 decided to give up during the second instance of evaluation.

\section{Statistical Analysis}

The t-Student test was used for pair samples in order to verify the existence of statistically meaning differences between the two instances of evaluation. The intention was to verify with the bi-varied co-relation if the variable Self-Consciousness of Appearance, Self-Evaluative Salience and Motivational Salience related to the Personality Traits, Optimism, Positive and Negative Affect, Self-Concept and Social Support Satisfaction. A 
multiple linear regression was used in order to guarantee attaining a parsimonious model with the possibility of predicting Self-Consciousness of Appearance, Self-Evaluative Salience and Motivational Salience as per the function of the independent variables (Neuroticism, Extraversion, Openness, Agreeableness, Conscientiousness, Optimism, Positive and Negative Affect, Self-concept and Social Support Satisfaction). Via Durbin-Watson statistics the presumption of independence and the VIF $(<5)$ were evaluated to diagnosis multicollinearity (Marôco, 2010), considering meaningful effects $p<.05$. In order to exploit eventual causal relations a Path Analysis was carried out with the objective of testing a causal model, evaluating the normality of the variables by the coefficients of asymmetry (SK) and kurtosis $(\mathrm{Ku})$ uni and multivariate, and the effects were considered to be meaningful with $p<.05$ (Marôco, 2014).

\section{RESULTS}

On Table 2 there are statistically meaningful differences between the evaluation carried out during the admittance period (moment 1) and 12-months after the surgery (moment 2) on Extraversion, Openness, Agreeableness, Conscientiousness, Self-Concept, and Self-Consciousness of Appearance.

As per the results of this study (table 3), one can confirm on the first evaluation that

Table 2

Variable Averages evaluated during the admittance versus 12-months after the surgery

\begin{tabular}{|c|c|c|c|c|c|c|}
\hline & \multicolumn{2}{|c|}{$\mathrm{M}(\mathrm{SD})$} & \multicolumn{2}{|c|}{$\begin{array}{c}95 \% \text { interval of trust of } \\
\text { the Difference }\end{array}$} & \multirow[t]{2}{*}{$t$} & \multirow{2}{*}{$p$} \\
\hline & Moment 1 & Moment 2 & Minimum & Maximum & & \\
\hline Neuroticism & $3.28(.72)$ & $3.24(.61)$ & -.20 & .29 & .37 & .710 \\
\hline Extroversion & $3.69(.46)$ & $3.05(.60)$ & .48 & .81 & 8.02 & $<.001$ \\
\hline Openness & $3.48(.49)$ & $3.05(.43)$ & .28 & .56 & 5.98 & $<.001$ \\
\hline Agreeableness & $3.49(.53)$ & $3.20(.48)$ & .12 & .45 & 3.37 & .001 \\
\hline Conscientiousness & $3.90(.45)$ & $2.99(.53)$ & .75 & 1.06 & 11.46 & $<.001$ \\
\hline Self-Concept & $12.60(2.17)$ & $14.22(2.15)$ & -2.35 & -.90 & -4.48 & $<.001$ \\
\hline Self-Consciousness of Appearance & $2.02(.50)$ & $3.85(1.34)$ & -2.17 & -1.49 & -10.76 & .000 \\
\hline Investment Schematic Appearance & $6.59(.1 .08)$ & $6.24(1.17)$ & -.07 & .76 & 1.68 & .098 \\
\hline Social Support Satisfaction & $11.54(2.28)$ & $11.86(2.31)$ & -1.09 & .47 & -.80 & .426 \\
\hline Optimism & $3.20(.74)$ & $3.31(.83)$ & -.23 & .01 & -1.90 & .062 \\
\hline Positive Affect & $3.15(.63)$ & $3.21(.59)$ & -.27 & .15 & -.550 & .584 \\
\hline Negative Affect & $2.19(.82)$ & $2.39(.79)$ & -.50 & .09 & -1.38 & .172 \\
\hline
\end{tabular}

the dimension Neuroticism and the perception Satisfaction of Social Support reveals a positive relation to Self-consciousness of Appearance, whilst Self-concept and Optimism reveal a negative relation. Negative Affect shows a positive relationship with Self-Evaluative Salience, whilst the Negative Affect relates positively to Motivational Salience. In comparison with the second evaluation Self-conscience of Appearance, it keeps a negative relation with Self-concept and a positive relation with Neuroticism. Self-Evaluative Salience shows a positive relation with most variables (Neuroticism; Extraversion; Openness; Agreeableness; Negative Affect; and Social Support Satisfaction), and negative relation with Self-concept. Motivational Salience reveals a weak relation with Amiability.

On the first evaluation, the multiple linear regression identifies Agreeableness $(\beta=-.36$; $t(56)=-2.12 ; p<.05)$ and Optimism $(\beta=$ 
$-.44 ; t(56)=-2.62 ; p<.05)$ as a meaningful predictor of Self-Consciousness of Appearance; Negative Affect $(\beta=.32 ; t(56)=2.32$; $p<.05)$ as a predictor of Self-Evaluative Salience and Positive Affect $(\beta=.34 ; t(56)=$ $.2 .50 ; p<.05)$ as a predictor of Motivational Salience. Agreeableness, Optimism and Negative and Positive Affect presented greater power for explaining the relation of Self-Consciousness of Appearance, Self-Evaluative Salience, and Motivational Salience. The second evaluation identifies Neuroticism $(\beta$ $=.49 ; t(56)=3.92 ; p<.001)$ and Negative Affect $(\beta=.34 ; t(56)=2.50 ; p<.05)$ as meaningful predictions of Self-Consciousness of Appearance. Regarding Self-Evaluative Salience, as a prediction of Neuroticism $(\beta=$ $.36 ; t(56)=2.76 ; p<.01)$. Neuroticism and Negative Affect presented greater power for explaining the relation of Self-Consciousness of Appearance and Self-Evaluative Salience (Table 4).

Trajectories were analyzed via a mediation model with the objective of evaluating the significance of the Negative Affect and Optimism on the levels of Self-Conscious- ness and Appearance, measured by the Schematic Investment of Appearance, and none showed any values of $S k$ and $K u$ that could indicate severe violation to Normal distribution $(|S k|<3$ e $|K u|<7-10)$. Figure 1 and 2 show the model with standard estimates of the coefficients of regression and the $R^{2}$ relating to the levels of Self-consciousness of Appearance. The model explains $30 \%$ of the variability of the levels of Self-consciousness of Appearance (Figure 1). The trajectories between Optimism and the Schematic Investment of Appearance $\left(\mathrm{b}_{\text {OptimismShematicInvestmentofAppea- }}\right.$ race $=.075 ; S E_{\mathrm{b}}=.082, Z=.919 ; p=.358 ; \beta_{\mathrm{Opt}}$ imismShematicInvestmentofAppearace $=.11$ ) and the Negative Affect and Self-consciousness of Appearance $b_{\text {NegativeAffectSelf-ConsciousnessofAppearance }}=.020$; $S E_{\mathrm{b}}=.068, Z=.297 ; p=.767 ; \beta_{\text {NegativeAffectSelf- }}$ ConsciousnessofAppearance $=.033$ ) are not statistically meaningful. The variable Optimism showed a total effect of -.27 over Self-consciousness of Appearance, with a direct effect of .075 and an indirect effect, measured by the Investment Schematic of Appearance, of .025.

On the second evaluation (Figure 2), the model explains $49 \%$ of the variability of the

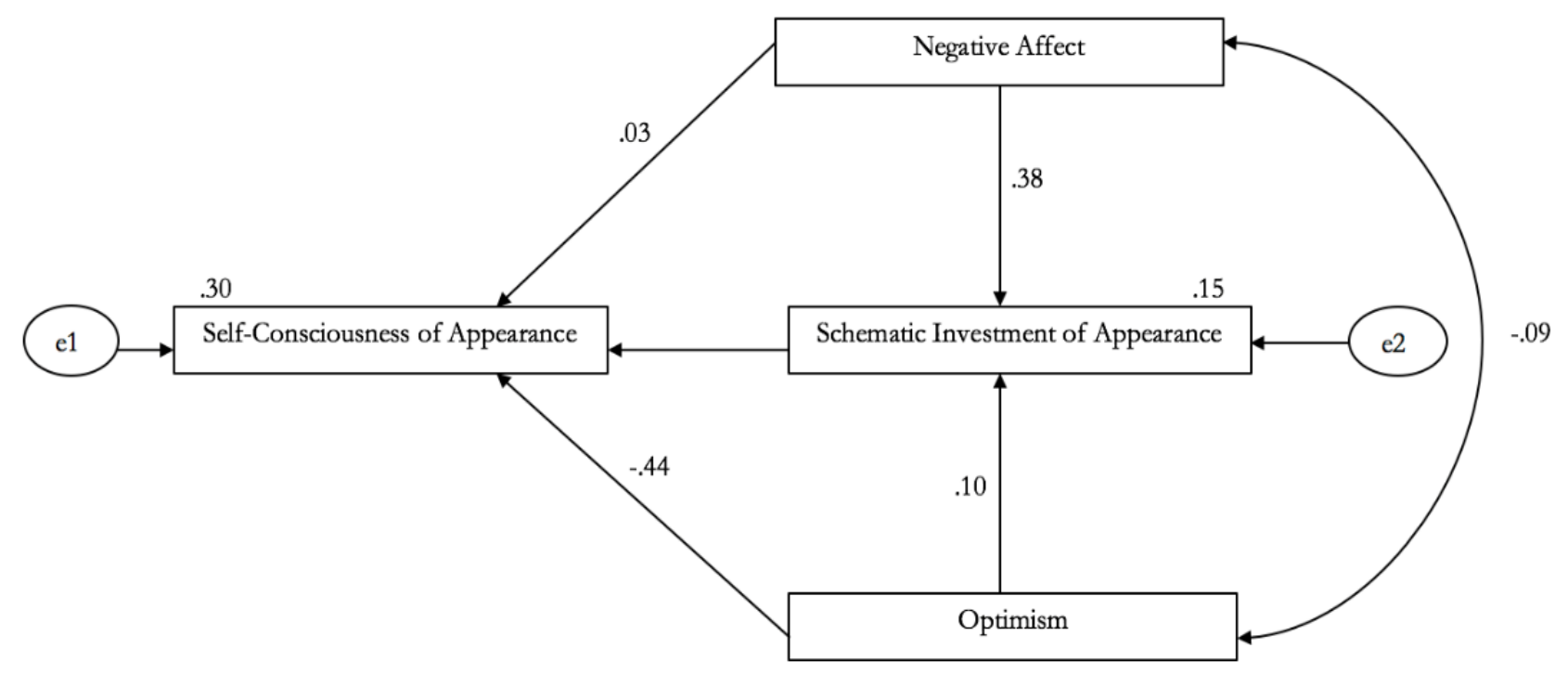

Figure 1 - Model of the measurement of the Schematic Investment of Appearance over the levels of Self-Consciousness of Appearance. With the exception of the trajectories Optimism $\rightarrow$ Schematic Investment of Appearance and Negative Affect $\rightarrow$ Self-Consciousness of Appearance. 


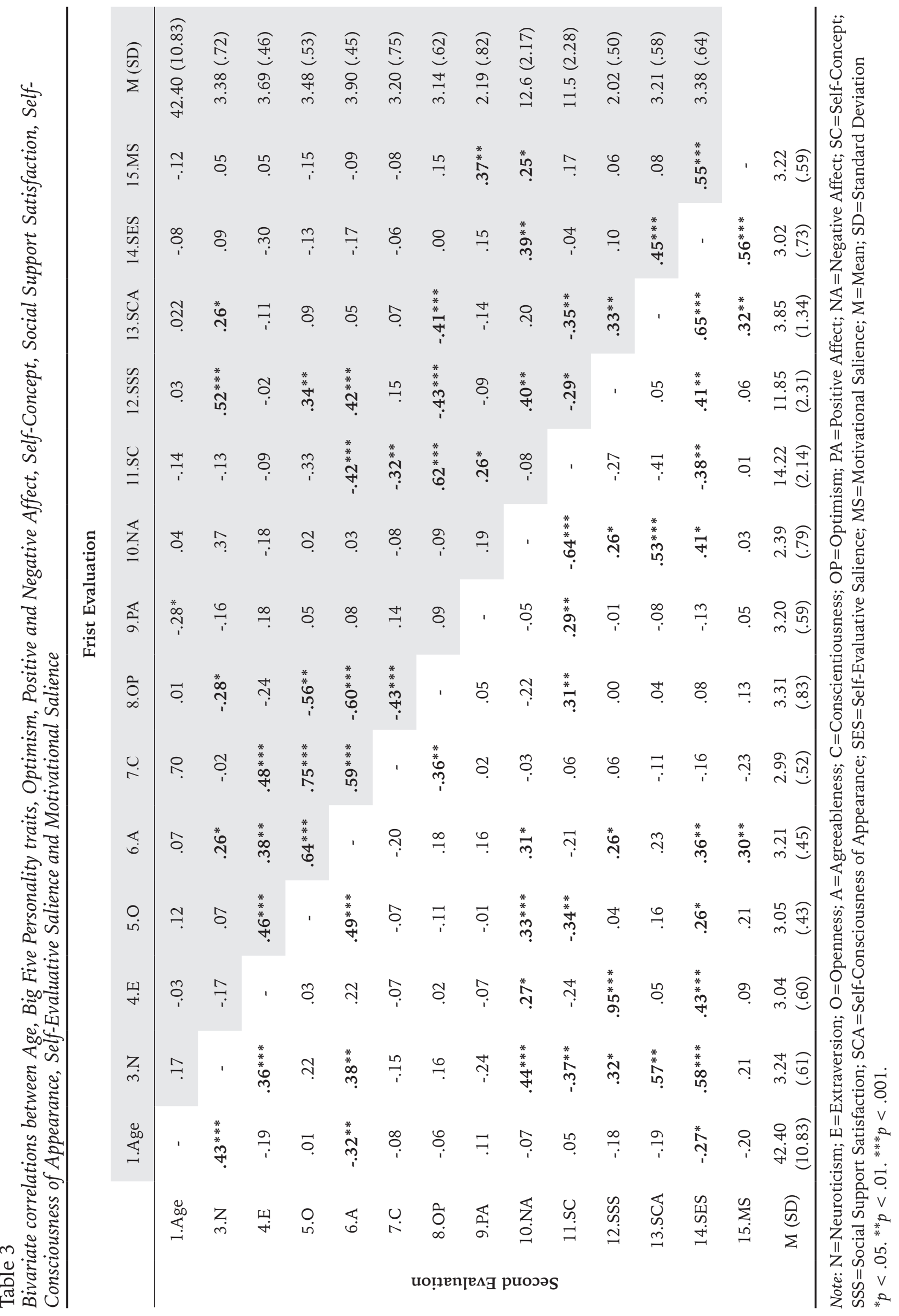




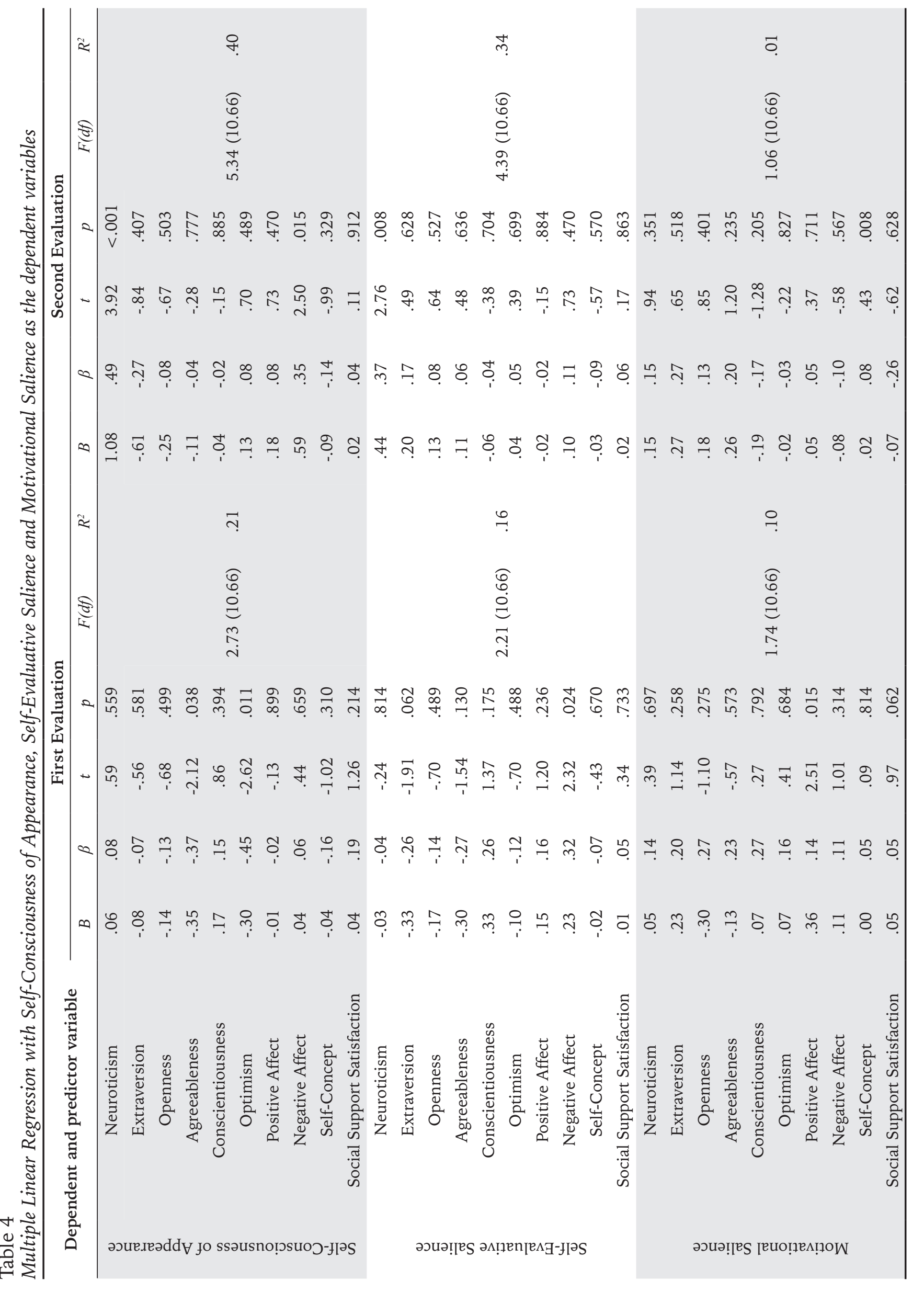


levels of Self-consciousness of Appearance. All trajectories are positive and statistically meaningful to the exception of the direct effect of Optimism over the measurement of the Investment Schematic and levels of Self-consciousness of Appearance ( $b_{\text {OptimismShematicInvestmento- }}$ fAppearace $=.134 ; S E_{\mathrm{b}}=.085, Z=1.579 ; p=.114$; $\beta_{\text {OptimismShematicInvestmentofAppearace }}=.19$ ) and Optimism and Self-consciousness of Appearance $\left(b_{\text {OptimismSelf-ConsciousnessofAppearance }}=.068 ; S E_{\mathrm{b}}=.074\right.$,
$Z=.925 ; p=.114 ; \beta_{\text {OptimismSelf-ConsciousnessofAppearance }}$ $=.085)$. The variable Negative Effect reveals a total effect of .48 over Self-consciousness of Appearance, with a direct effect of .339 and indirect effect, measured by the Schematic Investment of Appearance, of .141.

\section{DISCUSSION}

To contribute to the understanding of the psychological Adjustment to Acquired Facial

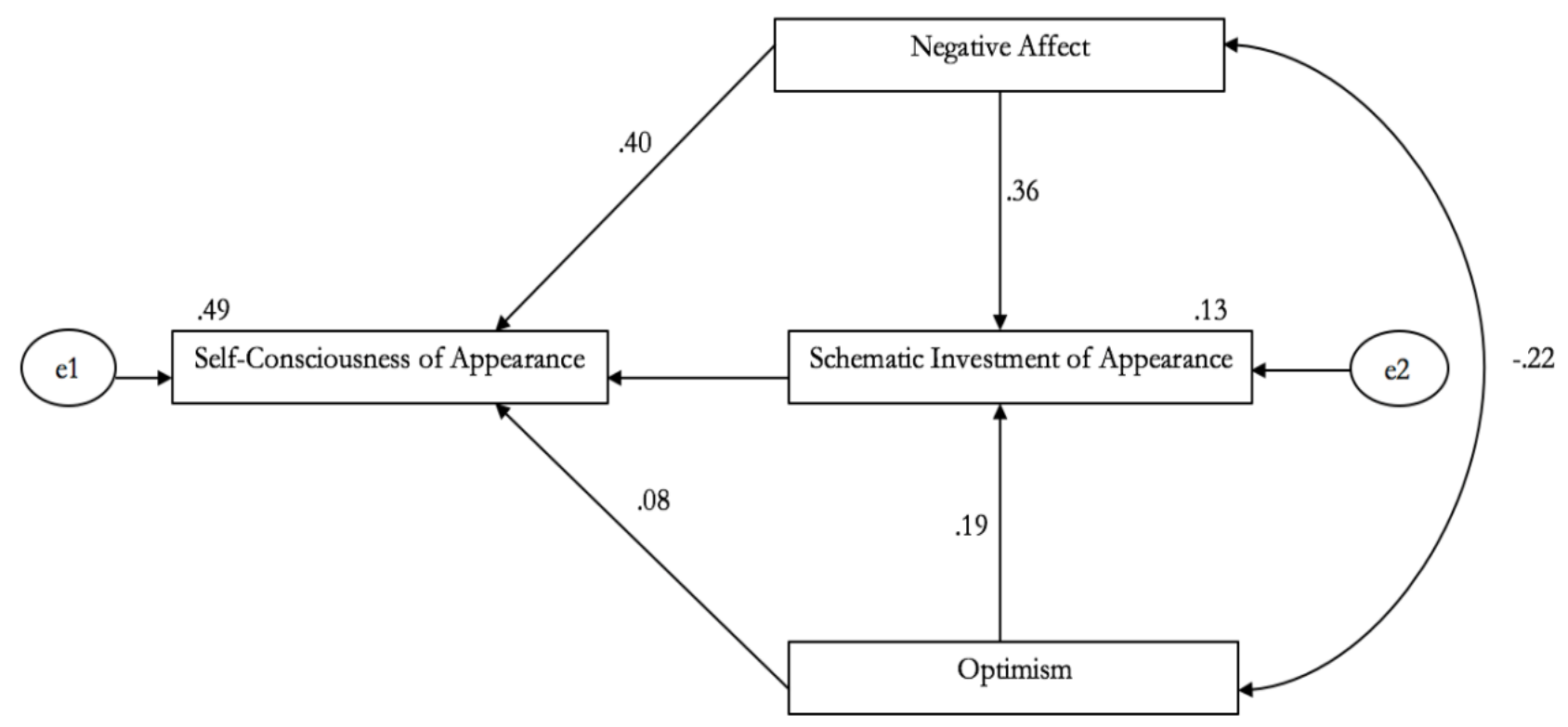

Figure 2 - Model of the measurement of the Schematic Investment of Appearance over the levels of Self-Consciousness of Appearance. With the exception of the trajectories Optimism $\rightarrow$ Schematic Investment of Appearance and Optimism $\rightarrow$ Self-Consciousness of Appearance.

Disfigurement, we decided to study in individuals, who after plastic/reconstructive surgery, suffer from acquired facial disfigurement. To do this, a longitudinal study was carried out to evaluate the differences between two instances, post-surgical and then after 12-months. At those moments we identified the predictors of Neuroticism, Extraversion, Openness, Agreeableness, Conscientiousness, Optimism, Positive and Negative Affect, Self-Concept and Social Support Satisfaction.

Results highlight meaningful statistical differences between the two instances.

Adverse life events, seem not to have any impact on the individuals' personality, however recent research and meta-analysis of older studies indicate, these changes could take place in five personality dimensions in different moments of an individual's' lifespan (Pedroso de Lima et al., 2014)

Concerns with appearance are complex and debilitating, this contributes to feelings of ineptitude, influencing various processes (Rosser et al., 2010). The acceptance to do plastic surgery is associated with personality factors, self-worth and self-evaluation of attraction(Swami, Chamorro-Premuzic, Bridges, \& Furnham, 2009).

The differences found in this study could be related to the fact that there's depersonalization feel when suffering from facial disfigurement (Brill et al., 2006). Adjustment levels 
to facial disfigurement are not static (Morris et al., 2007) because individuals have the need to invest in the adjustment to facial disfigurement (Partridge, 2003). A study carried out by (Swami, Taylor, and Carvalho, (2011) point out meaningful statistical differences between Personality traits and Body Dissatisfaction. They found evidence of an association between personality traits and facial appearance (Jones, Kramer, \& Ward, 2012).

In both evaluations made in this study, results reveal a meaningful positive co-relation between Self-consciousness of Appearance and the dimension of Neuroticism; the Negative Affect and the Self-Evaluation Salience, there being a greater relation to the second evaluation $\left(r_{\text {neuroticism }}=.26\right.$ vs $r_{\text {neuroticism }}$ $=.57)$ and the variable Negative Affect $\left(_{\text {negative }}\right.$ ${ }_{\text {affect }}=.39$ vs $\left.{ }_{\text {negative affect }}=.41\right)$.

When Sawani et al. (2013) evaluated the influence of personality traits in Self-consciousness of appearance they found meaningful correlations between neuroticism and the Self-consciousness of appearance, pointing towards an association between personality and the components of the evaluation of the body image.

Amiability and Optimism are considered to be predictors of the Self-consciousness of Appearance, and the Positive and Negative Affect predictors of Schematic Investment of Appearance in the first evaluation. Rumsey and Harcourt (2012), describe that a negative body image may strongly influence self-concept, social functioning and the quality of life of an individual as self-consciousness expresses itself as a key attribute to learn how to deal with a disfigurement (Bessell et al., 2010). Harris (1997), defends that levels of concern with appearance depend on the Self-consciousness of Appearance.

The second evaluation shows Neuroticism and Negative Affect as predictors of the levels of Self-consciousness of Appearance and Neuroticism as a predictor of Self-evaluation.
Leising and Zimmermann (2011) refer that the dispositions of personality (the influence and the trust on others, experiences of rage, feelings of guilt, shame, fear, sadness, accepting risks, amongst others) reflect the tendency on the manner by which the individual thinks, feels and behaves in a certain situation. A study led by Swami et al (2013) mentions that neuroticism is meaningfully associated with the body image and the appreciation of the body and that it can influence the negative perception of appearance.

The analysis of trajectories shows that Optimism and Negative Affect have different effects on both evaluations. Optimism has a direct effect on Self-consciousness of Appearance, having the schematic investment as the mediator of the negative effect on the Self-consciousness of Appearance on the first evaluation. Twelve months after surgery, Optimism no longer has a negative effect on Self-consciousness of Appearance, and the Negative Affect begins to have a direct effect. These results can be justified by the fact that, in the first evaluation, individuals may have been feeling more optimistic and show a tendency to have more favorable expectations regarding future events (Laranjeira, 2008). In accordance with (Turner, Goodin, and Lokey (2012) those who are able to integrate events and experiences in their life story show higher levels of wellness than those who are unable to do so. A poor adjustment to disfigurement may influence the individual to give a more negative meaning to appearance (Moss, 2005).

Although the adjustment process to appearance is influenced by various factors (Rumsey \& Harcourt, 2005), this study shows the influence of the personality traits and Self-concept in the adjustment to acquired facial disfigurement, having shown that the Schematic Investment and the Self-consciousness of appearance vary as per the adjustment of the individual to visible alterations to their face.

The conclusions of this study must be inter- 
preted within its context, taking into account its limitations. Although individuals show an acquired facial disfigurement, the dimension of the study did not allow for more research into more complex relations between the variables, or even to find meaningful effects, and it is possible that one Type II mistake could have occurred. Other limitations of this study include a large number of instruments used after the plastic/reconstructive surgery, and the results of this study might not represent well the experiences of those individuals suffering from a facial disfigurement, underestimating the force of the relation between the seriousness of the disfigurement and the psycho-social processes/results. Moss (2005) defends that a weaker adjustment is severe, and Social implications can influence the perception and degree of the severity ranging from inexistent to high. It's important to reinforce, in accordance to Elks (1990), that for a visible difference to be considered a disfigurement, there must be a negative reaction of the individual or of his surrounding environment to that visible difference.

Given the above limitations, a replication of this study is advised using a larger sample. We advise that the first evaluation should be carried out before surgery so that individuals could reply without the possible influence of variables such as pain, swelling, bruises, medication, amongst others. Another recommendation is to increase the follow-up period, evaluating them in two other instances, (with the objective of understanding their thoughts via the registration of their observed behavior and other collected data that might be considered relevant taken under a natural context).

In line with other authors, these results confirm that the adjustment to facial disfigurement is complex (Carr, Moss, \& Harris, 2005; Clarke et al., 2014; Partridge, 2003; Rumsey \& Harcourt, 2004, 2012). Nevertheless, this study contributes to a better understanding of the influence of personality traits, Self-concept and that perception of satisfaction with social support influence the manner by which the individual adjusts to an acquired facial disfigurement, suggesting further studies to evaluate the contextual influences and the intra-individual variation in the adjustment to acquired facial disfigurement.

\section{Acknowledgments:}

To the Internment Unit for Plastic and Reconstructive Surgery of the Hospital Centre Lisboa Norte (Hospital de Santa Maria); Professor Margarida Rebelo (Ph.D.) and Professor João Marôco (Ph.D.) for their cooperation and revision of the causal model (Figure 1 and 2).

\section{Conflict of Interests:}

The authors declare that there is no conflict of interests.

\section{Financing:}

The authors did not receive any financial support.

\section{REFERENCES}

Bessell, A., Clarke, A., Harcourt, D., Moss, T. P., \& Rumsey, N. (2010). Incorporating User Perspectives in the Design of an Online Intervention Tool for People with Visible Differences: Face IT. Behavioural and Cognitive Psychotherapy, 38(05), 577-596. DOI: $10.1017 /$ S1352465810000305

Bhattacharya, V. (2012). Management of soft tissue wounds of the face. Indian Journal of Plastics Surgery, 45(3), 436-443. DOI: 10.4103/0970-0358.105936

Bradbury, E. (2012). Meeting the psychological needs of patients with facial disfigurement. British Journal of Oral and Maxillofacial Surgery, 50(3), 193-196. DOI:10.1016/j.bjoms.2010.11.022

Brill, S. E., Clarke, A., Veale, D. M., \& Butler, P. E. M. (2006). Psychological management and body image issues in facial 
transplantation. Body Image, 3(1), 1-15. DOI: 10.1016/j.bodyim.2005.12.002

Callahan, C. (2005). Facial Disfigurement and Sense of Self in Head and Neck Cancer. Social Work in Health Care, 40(2), 73-87. DOI:10.1300/J010v40n02_05

Carr, T., Harris, D., \& James, C. (2000). The Derriford Appearance Scale (DAS-59): A new scale to measure individual responses to living with problems of appearance. British Journal of Health Psychology, 5(2), 201-215.DOI: 10.1348/135910700168865

Carr, T., Moss, T., \& Harris, D. (2005). The DAS24: a short form of the Derriford Appearance Scale DAS59 to measure individual responses to living with problems of appearance. British Journal of Health Psychology, 10(Pt 2), 285-298. DOI: 10.1348/135910705X27613

Cash, T. F. (2004). Body image: past, present, and future. Body Image, 1 (1), 1-5. https:// doi.org/10.1016/S1740-1445(03)00011-1

Cash, T. F., Melnyk, S. E., \& Hrabosky, J. I. (2004). The assessment of body image investment: an extensive revision of the appearance schemas inventory. The International Journal of Eating Disorders, 35(3), 305-316. DOI: 10.1002/eat.10264

Clarke, A., Thompson, A., Jenkinson, E., Rumsey, N., \& Newell, R. (2014). CBT for Appearance Anxiety: Psychosocial Interventions for Anxiety due to Visible Difference. United Kingdom: Wiley Blackwell.

Costa, E., Nogueira, T., de Souza-Lima, N., Mendonça, E., \& Leles, C. (2014). A qualitative study of the dimensions of patients' perceptions of facial disfigurement after head and neck cancer surgery. Spec Care Dentist. 34(3), 114-21. DOI: $10.1111 /$ scd.12039.

Csukly, G., Telek, R., Filipovits, D., Takács, B., Unoka, Z., \& Simon, L. (2011). What is the relationship between the recognition of emotions and core beliefs: Associations between the recognition of emotions in facial expressions and the maladaptive schemas in depressed patients. Journal of Behavior Therapy and Experimental Psychiatry, $42(1), \quad 129-137 . \quad$ DOI: $10.1016 / \mathrm{j}$. jbtep.2010.08.003

Elks, M. (1990). Another Look at Facial Disfigurement. Journal of Rehabilitation, 56, 36-40. Retrieved from http://www. thefreelibrary.com/_/print/PrintArticle. aspx?id $=8844427$

Galinha, I. C., \& Pais-Ribeiro, J. L. (2005). Contribuição para o estudo da versão Portuguesa da Positive and Negative Affect Schedule (PANAS): II - Estudo psicométrico. Análise Psicológica, 23(2), 219-227. Retrieved from http:// publicacoes.ispa.pt/index.php/ap/article/ viewFile/84/pdf

Gwanmesia, I., Clarke, A., \& Butler, P. E. M. (2011). Facial transplantation revisited: Findings from the very first public engagement exercise. International Journal of Surgery, 9(5), 433-436. DOI: 10.1016/j. ijsu.2011.04.005

Hagedoorn, M. \& Molleman, E. (2006). Facial disfigurement in patients with head and neck cancer: The role of social self-efficacy. Health Psychology, 25(5), 643-647. DOI: 10.1037/0278-6133.25.5.643

Harris, D. (1997). Types, causes and physical treatment of visible differences. In $\mathrm{R}$. Lawsdown, N. Rumsey, E. Bradbury, T. Carr, J. Partridge. Visibly different: Coping with disfigurement (pp. 79-90). United Kingdom: Butterworth Heinemann.

Jamrozik, A., Oraa Ali, M., Sarwer, D. B., \& Chatterjee, A. (2019). More than skin deep: Judgments of individuals with facial disfigurement. Psychology of Aesthetics, Creativity, and the Arts, 13(1), 117-129. DOI: $10.1037 /$ aca0000147

Jones, A. L., Kramer, R. S. S., \& Ward, R. (2012). Signals of personality and health: The contributions of facial shape, skin 
texture, and viewing angle. Journal of Experimental Psychology: Human Perception and Performance, 38(6), 1353-1361. DOI: $10.1037 / \mathrm{a} 0027078$

Kugaya, A., Akechi, T., Okamura, H., Mikami, I., \& Uchitomi, Y. (1999). Correlates of depressed mood in ambulatory head and neck cancer patients. PsychoOncology, 8(6), 494-499. DOI: 10.1002/ (SICI) $1099-1611(199911 / 12) 8$ : 6<494::AID-PON403>3.0.CO;2-M

Lansdown, R. (Ed.). (1997). Visibly different: coping with disfigurement. Oxford ; Boston: Butterworth-Heinemann.

Laranjeira, C. (2008). Tradução e validação Portuguesa do revised life orientation test (LOT-R). Universitas Psychologica, (7), 468-476. Retrieved from http://pepsic. bvsalud.org/pdf/up/v7n2/v7n2a13.pdf

Leising, D., \& Zimmermann, J. (2011). An integrative conceptual framework for assessing personality and personality pathology. Review of General Psychology, 15(4), 317-330. DOI: 10.1037/a0025070

Losee, J., Fletcher, D., \& Gorantla, V. (2012), Human facila allotransplantation: patient selection and pertinent considerations. Journal of Cranofacial Surgery, 23(1), 260-264. DOI:10.1097/ SCS.0b013e318241b958

Maddern, L. H., Cadogan, J. C., \& Emerson, M. P. (2006). 'Outlook': A Psychological Service for Children with a Different Appearance. Clinical Child Psychology and Psychiatry, 11(3), 431-443. DOI: $10.1177 / 1359104506064987$

Magalhães, E., Salgueira, A., Gonzalez, A.-J., Costa, J. J., Costa, M. J., Costa, P., \& Lima, M. P. de. (2014). NEO-FFI: Psychometric properties of a short personality inventory in the Portuguese context. Psicologia: Reflexão e Crítica, 27(4), 642-657. DOI: 10.1590/1678-7153.201427405

Marôco, J. (2010). Análise Estatística com o PASW Statistics (ex SPSS). Lisboa: ReportNumber.
Marôco, J. (2014). Análise de Equações Estruturais: fundamentos teóricos, software \& aplicações (2a Edição). Lisboa: ReportNumber.

Moreira, H., \& Canavarro, M. (2007). The Portuguese version of the Derriford Appearance Scale - 24 (Unpublished manuscript). Department of Psychology, Faculty of Psychology and Education Sciences, Coimbra, Portugal.

Morris, P., Bradley, A., Doyal, L., Earley, M., Hagen, P., Milling, M., \& Rumsey, N. (2007). Face Transplantation: A Review of the Technical, Immunological, Psychological and Clinical Issues with Recommendations for Good Practice: Transplantation, 83(2), 109-128. DOI: 10.1097/01.tp.0000254201.89012.ae

Moss, T. (2005). The relationships between objective and subjective ratings of disfigurement severity, and psychological adjustment. Body Image, 2(2), 151-159. DOI: $10.1016 /$ j.bodyim.2005.03.004

Moss, T., \& Carr, T. (2004). Understanding adjustment to disfigurement: the role of the self-concept. Psychology \& Health, 19(6), 737-748. DOI: 10.1080/08870440410001722967

Nazaré, B., Moreira, H., \& Canavarro, M. C. (2010). Uma perspectiva cognitivocomportamental sobre o investimento esquemático na aparência: Estudos psicométricos do Inventário de Esquemas sobre a Aparência (ASIR). Laboratório de Psicologia, (8), 21-36. Retrieved from https://estudogeral. sib.uc.pt/bitstream/10316/14292/1/ Vers\%C3\%A3o\%20final.pdf

Partridge, J. (2003). Changing Faces: the challenge of facial disfigurement (4.a ed.). London: A changing Faces Publication.

Pedroso de Lima, M. P. de L., Magalhães, E., Salgueira, A., Gonzalez, A.-J., Costa, J. J., Costa, M. J., \& Costa, P. (2014). A versão portuguesa do NEO-FFI: Caracterização em função da idade, género e escolaridade. 
Psicologia, 28(2). DOI: 10.17575/rpsicol. v28i2.534

Ribeiro, J. (2011). Escala de Satisfação com o Suporte Social (Placebo Editora). Lisboa.

Rosser, B. A., Moss, T., \& Rumsey, N. (2010). Attentional and interpretative biases in appearance concern: An investigation of biases in appearance-related information processing. Body Image, 7(3), 251-254. DOI: $10.1016 /$ j.bodyim.2010.02.007

Rumsey, N., \& Harcourt, D. (2004). Body image and disfigurement: issues and interventions. Body Image, 1(1), 83-97. DOI: $10.1016 /$ S1740-1445(03)00005-6

Rumsey, N., \& Harcourt, D. (2005). The psychology of appearance. Maidenhead, England; New York: Open University Press.

Rumsey, N., \& Harcourt, D. (Eds.). (2012). The Oxford handbook of the psychology of appearance. Oxford: Oxford University Press.

Soni, C. V., Barker, J. H., Pushpakumar, S. B., Furr, L. A., Cunningham, M., Banis, J. C., \& Frank, J. (2010). Psychosocial considerations in facial transplantation. Burns, 36(7), 959-964. DOI: /10.1016/j. burns.2010.01.012

Swami, V., Chamorro-Premuzic, T., Bridges, S., \& Furnham, A. (2009). Acceptance of cosmetic surgery: Personality and individual difference predictors. Body Image, 6(1), 7-13. https://doi. org/10.1016/j.bodyim.2008.09.004

Swami, V., Taylor, R., \& Carvalho, C. (2011). Body dissatisfaction assessed by the Photographic Figure Rating Scale is associated with sociocultural, personality, and media influences: Body dissatisfaction. Scandinavian Journal of Psychology, 52(1), 57-63. DOI:/10.1111/ j.1467-9450.2010.00836.x

Swami, V., Tran, U. S., Brooks, L. H., Kanaan, L., Luesse, E.-M., Nader, I. W., ... Voracek, M. (2013). Body image and personality: Associations between the Big Five Personality Factors, actual-ideal weight discrepancy, and body appreciation: Body Image and Personality. Scandinavian Journal of Psychology, 54(2), 146-151. DOI:/10.1111/sjop. 12014

Tagkalakis, P., \& Demiri, E. (2009). A fearavoidance model in facial burn body image disturbance. Annals of Burns and Fire Disasters, 22, 203-207. Retrieved from http://www.ncbi.nlm.nih.gov/pmc/ articles/ PMC3188186/pdf/Ann-Burnsand-Fire-Disasters-22-203.pdf

Turner, J. E., Goodin, J. B., \& Lokey, C. (2012). Exploring the Roles of Emotions, Motivations, Self-Efficacy, and Secondary Control Following Critical Unexpected Life Events. Journal of Adult Development, 19(4), 215-227.DOI: 10.1007/s10804012-9148-0

Vaz Serra, A. (1986). O «Inventário Clínico de Auto-Conceito». Psiquiatria Clínica, 7, 67-84. Retrieved from http://baes.ua.pt/ handle/10849/82

Wang T, Lu M, Kuo P, Chen, Y., Lee, S., \& Liang, S. (2018). Influences of facial disfigurement and social support for psychosocial adjustment among patients with oral cancer in Taiwan: a crosssectional study. British Medical Journal Open, 8:e023670. DOI: 10.1136/bmjopen-2018023670 